\title{
DMB+, a General Data Transmission Technique
}

\author{
Guoyu Wang ${ }^{1,2}$ and Hongsheng Zhang ${ }^{*}$ \\ ${ }^{1}$ College of Electronic Engineering, Chongqing University of Posts and Telecommunications \\ Chongqing, 400065 - China \\ [e-mail: zhanghs@cqupt.edu.cn] \\ ${ }^{2}$ School of Science, Hubei University of Technology \\ Wuhan, 430068 - China \\ [e-mail: wanggyb@cqupt.edu.cn] \\ *Corresponding author: Hongsheng Zhang
}

Received April 26, 2019; revised July 16, 2019; accepted August 19, 2019;

published May 31, 2020

\begin{abstract}
Developed from Digital Multimedia Broadcasting (DMB), DMB+ changes the application focus fundamentally. The plus symbol "+" indicates that DMB+ is no longer for digital radio/videos, instead it works as a general data transmission technique. The merits of wireless transmission, broad coverage, high quality, information security and low building/maintenance cost make DMB + suitable for a wide range of applications with numerous terminals and users, such as public information release, alarm and administration etc. The concept of $\mathrm{DMB}+$ base station enables $\mathrm{DMB}+$ to be used in building independent networks and for remote control and management, as well as for Industry 4.0. DMB+ will access into a new field that till now has been dominated by communication techniques, will open a huge commercial opportunity.
\end{abstract}

Keywords: DAB, DMB, DMB+, emergency warning, networking

This work was supported in part by the National Natural Science Foundation of China under Grant 61401051, the Major Industrial Originality Technological Innovation Project of Jiangsu Province under Grant BO2016001, and the Chongqing Scientific and Technical Programs under Grant cstc2019jscx-msxmX0079, cstc2016zdcy-ztzx0038, cstc2017zdcy-zdyf0166. The authors want to thank Dr. Mingying Lu for her pioneering work and Dr. D Renshaw, University of Edinburgh, Professor L Chen, University of Surrey, for assistance with writing this paper. 


\section{Introduction}

THE primary intention of digital broadcasting is to replace conventional analog radio, such as AM and FM. Digital audio broadcasting (DAB) [1] and Digital multimedia broadcasting (DMB) [2] have many advantages over analogue. They achieve high quality and spectrum efficiency. They can transmit several programs simultaneously over wide area with only one transmitter at low power, thus, digital broadcasting offers a greener, more economically efficient solution [3]-[5].

However, the importance of radio, even digitized, has been declining with the fast development of other forms of communication in decades. Stand-alone personal DAB/DMB receivers cannot achieve as large market as that of smart phones and internet terminals. On the other hand, people now tend to rely on mobile phone and internet too much, ignoring their deficiencies. In many situations communication connection may fail when needed most. Actually, digital broadcasting has inherent advantages which can overcome those problems. Thus, digital broadcasting should not be limited within the field of radio/video programs. It is worth exploring wider and more important functions, to turn the digital broadcasting into a general data transmission technique, as a complimentary addition to the existing information and communication technology (ICT) [6]-[7]. We define the new direction and applications as Digital Multimedia Broadcasting Plus (DMB+).

The significant difference between DMB+ and DMB is just like that between smart phone and common cell phone. The cell phone is for conventional voice/text contact only but smart phone offers much more advanced functions, leading to a wide range of new E-services. Similarly, DMB+ offers more features and broader usages than DMB does. Along the new direction, $\mathrm{DMB}+$ will revolutionalise the $\mathrm{DAB}$ and $\mathrm{DMB}$ research and market.

\section{Why DMB+ Needed}

\subsection{Make up Gaps in Existing ICT}

Broadcasting can cover unlimited numbers of terminals in the coverage area simultaneously, while communication service can only serve limited users, e.g., at times when too many users attempt to access the service, the local base station becomes overloaded and worst-case nobody can access [8]-[9]. Digital radios usually hardly ever pause, have a slow response, or break down, which inevitably happens, from time to time, with communication networks. Broadcasting is more robust, can survive serious natural disasters where other communication networks are destroyed [10]. It is a fatal defect for a communication network to fail to work in emergency situations. Broadcasting systems are simple and easier to maintain, while other networks, being complicated and difficult to maintain, may take more time to repair, should they fail. Also, broadcast systems are much more cost effective.

However, broadcasting industry did not pay enough attention to explore new applications to show its advantages over other techniques. Taking classroom teaching as an example, it requires fluent and smooth delivery of content and do not tolerate any interruption. Other examples include public information release by units and government sections, such as precaution and alarm at critic time. Smart city application needs a reliable network without spam and hacker attacks. However DMB cannot be used for these directly because new functions, new services, and new products are needed. These new direction and applications are then defined as $\mathrm{DMB}+$. The plus "+" signifies that it is much more than radio programs, 
and works as a general data transmission broadcasting platform, mainly used by units and government sections for public applications of information release, alarm and administration etc.

$\mathrm{DMB}+$ abides by the same standards as $\mathrm{DAB}[1]$ and $\mathrm{DMB}$ [2] to maintain the compatibility with them. $\mathrm{DMB}+$ supports all the functions which $\mathrm{DAB}$ and $\mathrm{DMB}$ have. New DMB+ functionalities are implemented mainly by exploiting the reserved data in the $\mathrm{DAB}$ standard instead of modifying the standard. $\mathrm{DAB}$ and $\mathrm{DMB}$ systems can be upgraded to $\mathrm{DMB}+$ using the following techniques that we have developed.

\subsection{Services for Administration/Alarm}

People may intuitively think that communication is the first choice for informing large populations due to the fact that most people have mobile phones and access the internet. However, there are circumstances where this is not the case, e.g., severe earthquakes during the past decades in China and Japan, where the only way to get information in central disaster areas was by listening to radio when other forms of communication infrastructure were broken and all traffic was cut off [10]-[12]. Broadcasting, in all countries, is an indispensable part in their national emergency warning systems [13]. In recent years, many researches have been carried out to build a more powerful alarm system with the new digital broadcast techniques [14]-[17]. DMB+ greatly enhances the functions of precaution, alarm, and rescue organization.

We also noticed that, even in normal times, it is not a good idea to send key information to large numbers of personal terminals such as mobile phones simultaneously. The reasons are: 1 ) technically it can be impossible when the number is very large, e.g., hundreds of thousands, or millions; 2) people receive too many messages everyday so they may not read every one; 3 ) most importantly people may not believe the information, even if they have read it.

Therefore in those circumstances, we must rely on other competent platforms instead of existing commercial communication networks.

It can be argued that, with the progress of communication techniques, these weaknesses will be overcome. We argue, however, that the disadvantages are intrinsic, and will become worse for the coming 5G. Alternative techniques should be employed to do the things they are suited to, thereby diverting information flow and so helping prevent communication networks from becoming over-crowd.

Broadcasting has its own problem to be solved for the administration purpose. The feature of user selection can reduce its effectiveness. Listeners may select other channels and miss critical information. Internet and smart phones have the same problem. Important messages may be ignored or submerged by spam or less important content. Also personal terminals and TV sets at home only cover a single person or one family.

$\mathrm{DMB}+$ adopts a new methodology to address these problems.

1) Instead of using personal devices such as radio, or smart phones, public terminals such as loudspeakers, LED/LCD screens are installed in observable positions of public areas. Only officially authorized content is allowed to be released to them, so people will know that all information is important and will pay attention.

2) All public terminals are triggered and controlled by transmitting signals. Viewers and listeners have no right of switching off, or selecting other content. In emergency, all terminals will be "woken up" automatically, within seconds and can reach almost everyone immediately. 
3) Learning from social network service (SNS), DMB+ programing needs to be easy, multi-access, and modernized.

\subsection{Potential Applications}

$\mathrm{DMB}+$ is ideally used for administration information by all levels of authorities. DMB+ also finds broad applications with numerous terminals and users, such as in schools and public areas, as well as for special applications of smart cities and public safety etc. The more people there are, the greater it is needed for a system like DMB+ for services and organization.

$\mathrm{DMB}+$ mainly works unidirectionally for most applications. With the installed terminals carrying out ID checking and content encryption, the system can be safer than commercial communication networks. It needs to be pointed out that, the shortcoming of unidirectional can sometime become an advantage. Hacker attacks, spam and false information are unavoidable for bidirectional networks but not for unidirectional system. The unidirectional feature sometime ensures authority.

However bidirectional connection may be critical for some circumstances. This can be achieved by combining other wireless techniques into $\mathrm{DMB}+$ system or implementing bidirectional connection between $\mathrm{DMB}+$ transmitters. We call this enhanced transmitter as $\mathrm{DMB}+$ base station which will open up more valuable applications. The high time precision, wireless over long distance, and low cost make the $\mathrm{DMB}+$ base station unique in building independent networks and for remote control and management, as well as for Industry 4.0.

The existing industrial networks, as well as the coming 5G, are not able to satisfy the stringent automation demands [18]-[19]. The Industry 4.0 faces a great challenge of high real-time and data synchronization among vast amount of devices. Although the Ethernet time-sensitive networking (TSN) has shown its potential for real-time industrial automation applications, it has not been well commercialized and has to overcome the obstacle of higher configuration efforts [19]. Therefore DMB + might be one good candidate as the data exchanging basis for implementing Industry 4.0.

\section{Key Techniques}

\subsection{DMB+ System Structure}

A common $\mathrm{DMB}+$ scheme is illustrated in Fig. 1. It consists of a DMB+ transmitter and various $\mathrm{DMB}+$ terminals, mainly public terminals e.g., loudspeakers, LCD screens and LED screens, as well as personal DAB receivers. The emitting power varies from milliwatts to kilowatts to provide coverage from several meters to dozens of kilometers. All the messages are sent from the $\mathrm{DMB}+$ transmitter to the receivers wirelessly, making the whole system very compact and easy to maintain.

Differing from the traditional DAB/DMB radio programs, $\mathrm{DMB}+$ can be easily operated by non-professional users to send messages to intended terminals. This requires coordination in both the transmitter and receiving modules. 


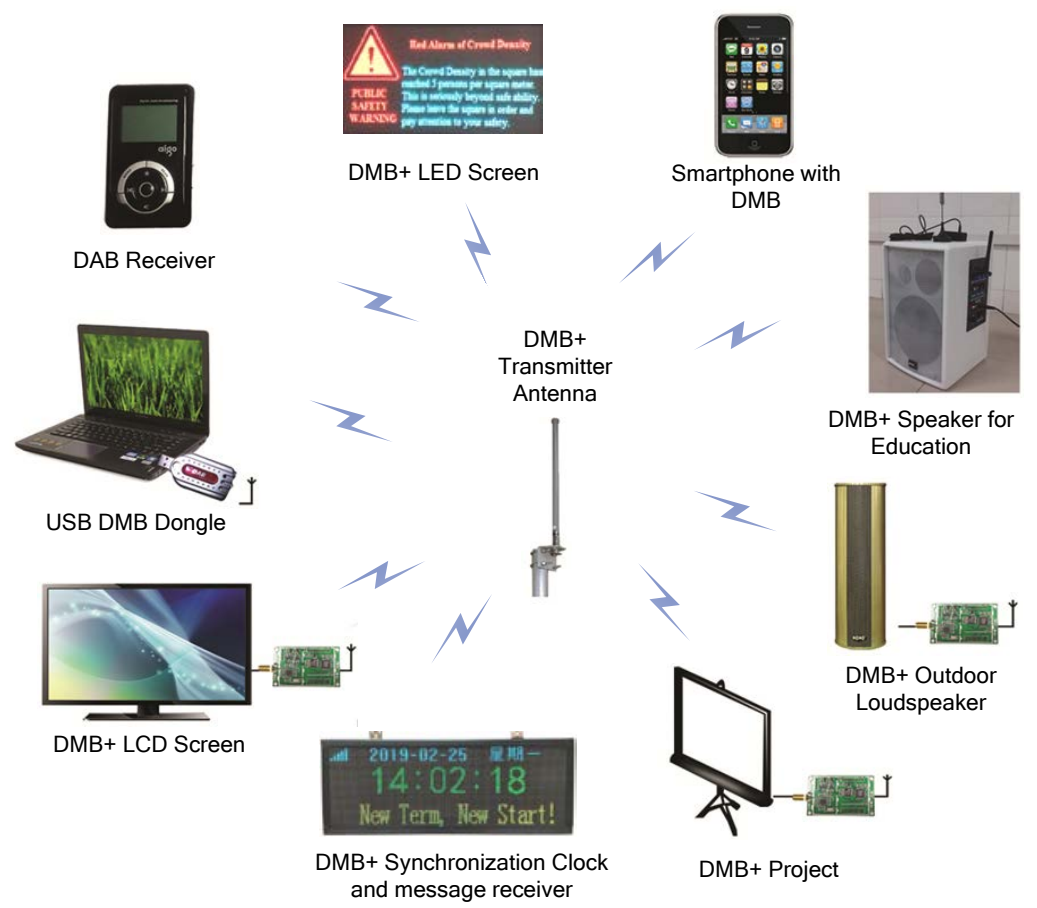

Fig. 1. Structure of the DMB+ platform

\subsection{High Integration DMB+ Transmitter}

The commercially available $\mathrm{DAB}$ transmitters used by professional radio stations are cumbersome and expensive. $\mathrm{DMB}+$ needs flexible and low-cost transmitters for wide usage. The transmitter also needs special control abilities to benefit data transmission. Such a DMB+ transmitter is designed as in Fig. 2.

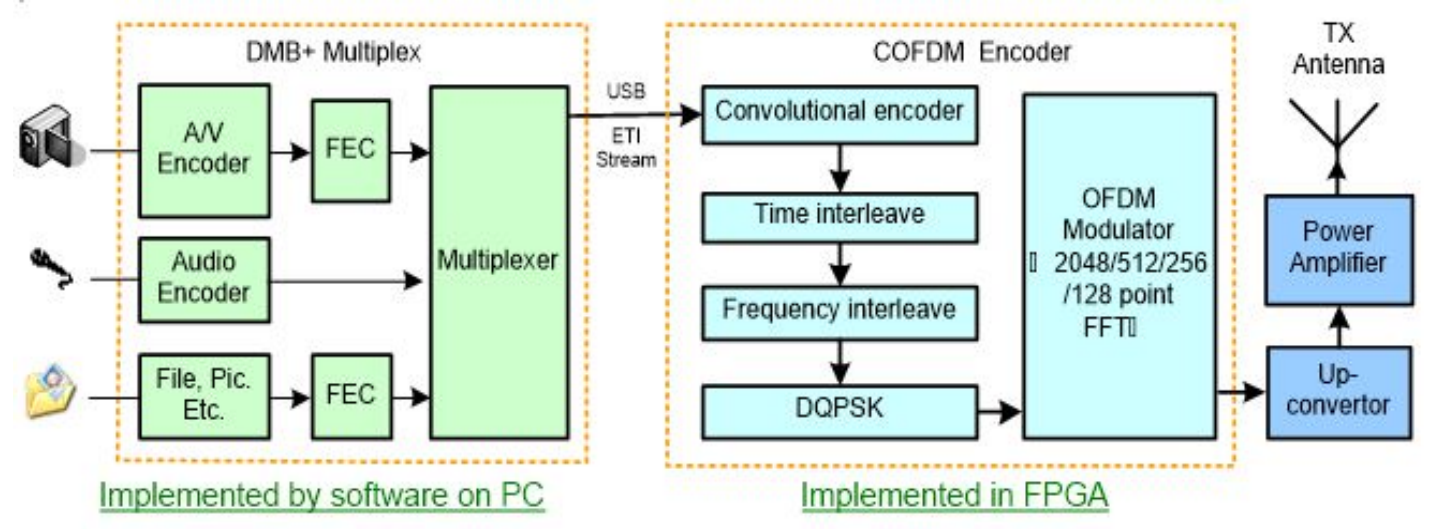

Fig. 2. Block diagram of the DMB+ transmitter.

Due to algorithm optimization, the coded orthogonal frequency division multiplex (COFDM) encoder, which is the core part of the DAB transmitter, is integrated in a single, low cost FPGA chip with only $10 \mathrm{~K}$ logic elements. The audio/video encoders, ensemble multiplexer and Ensemble Transport Interface (ETI) stream generator are all implemented by 
software on a PC, which provides high flexibility for different DMB+ applications. The ETI data, with a bit rate of only $2400 \mathrm{kbps}$, is fed to the COFDM encoder through a USB interface. The output of the COFDM encoder is then up-converted to the RF domain and amplified for desired coverage.

Fig. 3 exhibits the circuit board of the transmitter. It has a size of $19 \mathrm{~cm}(\mathrm{~L}) * 11 \mathrm{~cm}(\mathrm{~W}) * 1.2$ $\mathrm{cm}(\mathrm{H})$. The power supply can be either DC $7.5 \mathrm{~V}$ or $12 \mathrm{~V}$ with current less than $400 \mathrm{~mA}$. The small size and the low power features enable the $\mathrm{DMB}+$ transmitter be portable for flexible use, and be powered by battery cells when emergency.

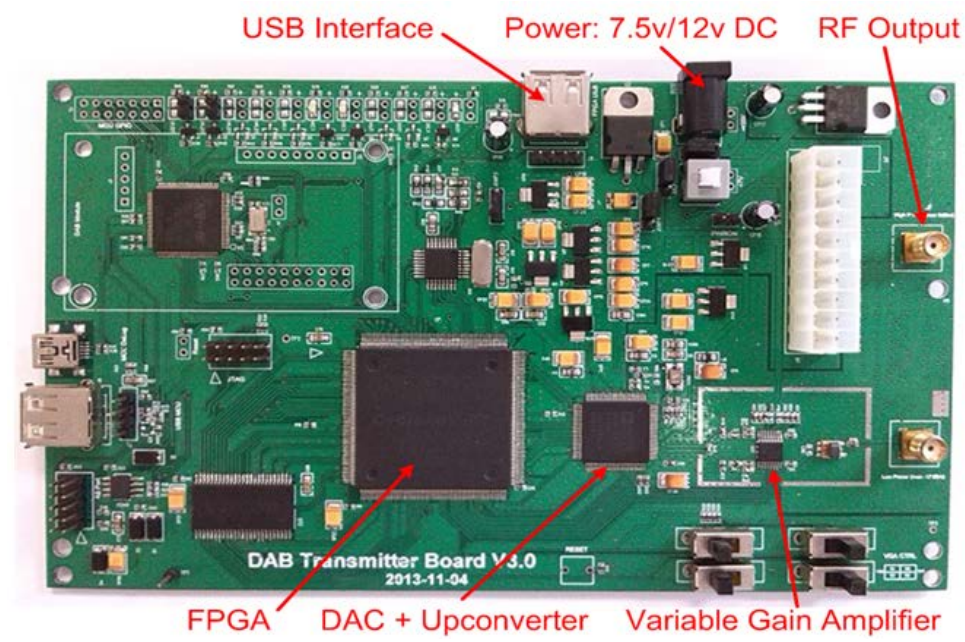

Fig. 3. Core board of the $\mathrm{DMB}+$ transmitter.

\subsection{DMB+ Receiving Module with Terminal Selection}

There are already many commercial DAB/DMB receiving modules available in the market. The module usually consists of RF tuner, analog to digital converter (ADC), DAB/DMB baseband decoder and a micro controller chip (MCU), as illustrated in Fig. 4(a). Some $\mathrm{DAB} / \mathrm{DMB}$ baseband chips have already integrated $\mathrm{ADC}$ and $\mathrm{MCU}$, so the receiving module can be very small in size. The MCU controls the tuning and demodulating operations through the I2C and SPI interfaces of the chips. The MCU also reads the fast information channel (FIC) data from the baseband decoder, decodes the FIC data and displays the DAB/DMB program information for user selection. The $\mathrm{DMB}+$ receiving module shares same structure with the $\mathrm{DAB} / \mathrm{DMB}$ receiving modules.

In contrast to the traditional $\mathrm{DAB} / \mathrm{DMB}$ receiving module, each $\mathrm{DMB}+$ receiving module has a unique ID and can be selected by the transmitter using the terminal selection technology [20]. An ID selection table, which contains the desired terminal IDs of each program, is transferred in the FIC at the transmitting side. The DMB+ receiver decodes the FIC to detect if its ID locates in any program's ID selection table. If yes, the receiver automatically selects and decodes that program. The detection is done periodically to guarantee any changes of terminal selection can be responded to in time. With terminal selection, all the DMB+terminals can run in unmanned mode and be controlled and evoked remotely by the transmitter.

The terminal selection is performed by the MCU software, so any legacy DAB/DMB receiving modules can be easily upgraded to $\mathrm{DMB}+$ receiving modules by software updating. Fig. 4(b) shows the photo of a DMB+ receiving module based on the DAB baseband chips customized designed previously [21]-[22]. 


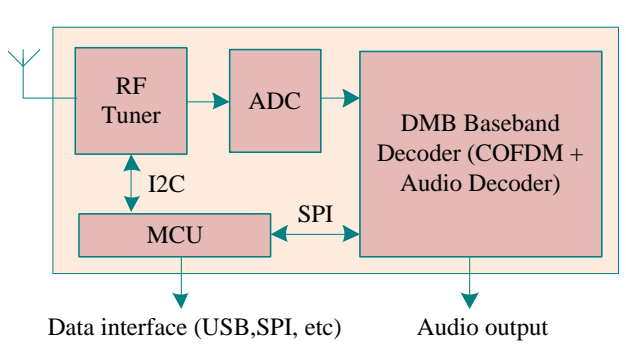

(a)

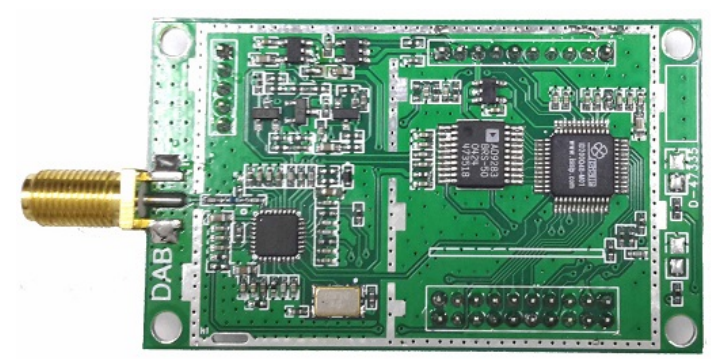

(b)

Fig. 4. Structure and the photo of the $\mathrm{DMB}+$ receiving module.

\subsection{DMB+ Receivers}

Based on the $\mathrm{DMB}+$ receiving module, many types of $\mathrm{DMB}+$ receivers can be designed to drive the loudspeakers, the LED screens and the LCD screens, etc. Because the terminal selection method is applied, all the receivers have the significant characters that they can run automatically without any user operation.

For the loudspeakers, the $\mathrm{DMB}+$ receiving module can be directly connected because most $\mathrm{DAB} / \mathrm{DMB}$ baseband chips have audio decoders and audio output. Because a loudspeaker usually has several audio inputs, plugging a $\mathrm{DMB}+$ receiver does not affect its normal functions, while instead, enables it to automatically play the $\mathrm{DMB}+$ audio when necessary.

For the LED screens, an external processor is needed to read data from the DMB+ receiving module and conduct post-processing to drive the LED screens. The existing LED screens are either asynchronous or synchronous. We have designed the DMB+ receivers for the both kinds [20]. The reported DMB+ receivers can be easily installed to the existing LED screens without affecting their normal usage and without any modifications on their hardware. Because many LED screens are fixed in position, an extended terminal selection method using GPS location can be applied [20].

For the LCD screens, because nowadays most of them are smart LCD screens with Android OS, the data post-processing can be done by an App running in the screen. The DMB+ receiving module is connected to the LCD screen via the USB port. The terminal ID and the tuning frequency are set by the user when the App runs at the first time. Then, the App configures the $\mathrm{DMB}+$ receiving module to tune the specified frequency and automatically receive the $\mathrm{DMB}+$ data using the terminal selection method. The received data are further processed by the App and displayed on the screen with a user friendly interface.

Various receivers are designed to comply with the common used public terminals of loudspeakers, LED screens and LCD screens without any affections on their normal functions. This means that, all the existing public terminals can be easily upgraded to $\mathrm{DMB}+$ terminals by simply plugging a $\mathrm{DMB}+$ receiver to them. Because the $\mathrm{DMB}+$ receiving module is simple and low-power, some terminals can even be powered by solar or wind energy sources. This would be very useful in remote areas and in heavy disasters where the electrical power is outage. Fig. 5 gives the photos of some DMB+t terminals. 


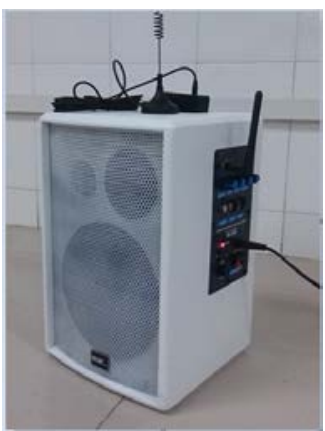

(a)

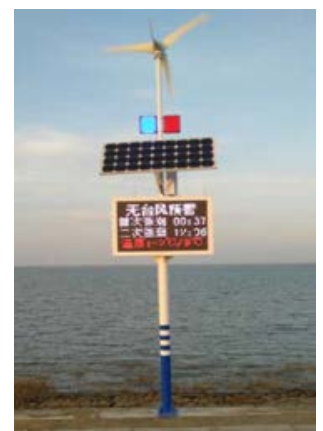

(b)

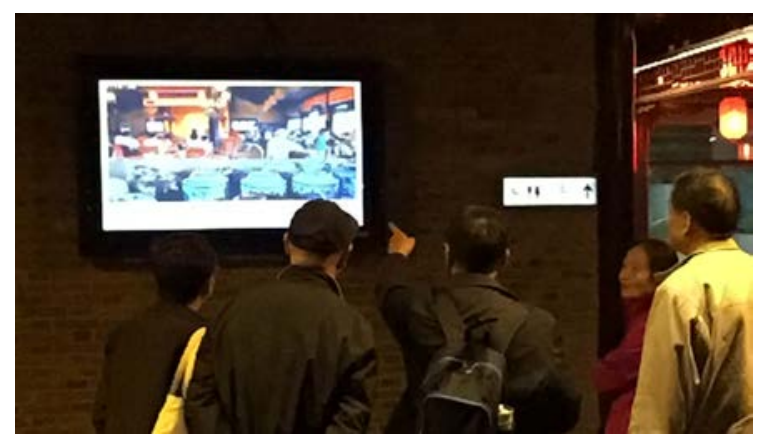

(c)

Fig. 5. Some DMB+ terminals. (a) a DMB+ loudspeaker in classroom, (b) a DMB+ LED screen powered by solar and wind energy at seaside, (c) a DMB+ LCD screen in a scenic spot.

\subsection{DMB+ Base Station}

Two unidirectional transmitters sending/receiving data to/from each other can achieve pseudo bi-directionality. In this way, special communications can be established when both sides have functioning receivers and transmitters [20].

The above mentioned high integration and flexible $\mathrm{DMB}+$ transmitter makes it easy to integrate the DMB+ transmitter and the receiver together, as illustrated in Fig. 6. A USB DMB dongle [23] is used as the $\mathrm{DMB}+$ receiver. A control software is designed to arrange both the transmitting and the receiving processes in an orderly manner. A dedicated bidirectional communication channel (BCC) is allocated in each transmitter to carry the communication data. The BCC configurations and the communication commands are carried in FIG3/7, a reserved FIG type in the DAB standard.

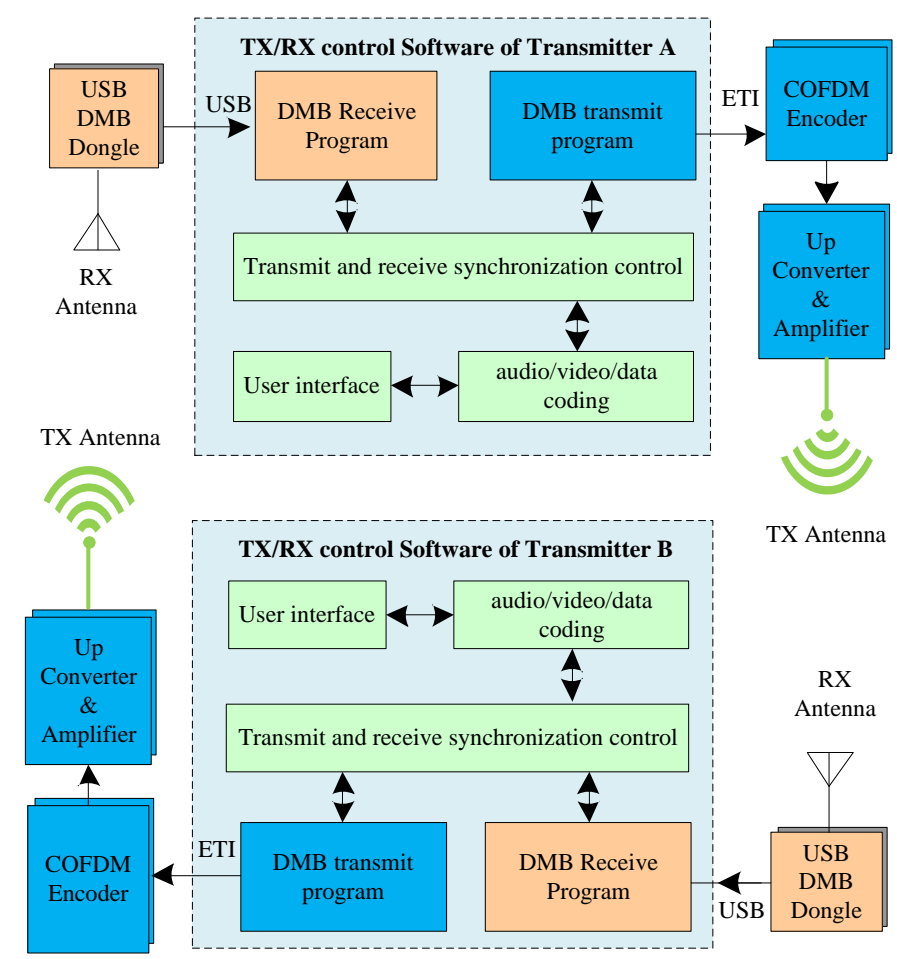

Fig. 6. The schematic diagram of the DMB+ bidirectional function 
The $\mathrm{DMB}+$ transmitter with wireless receiving ability can be further extended to a DMB+ base station, which communicates with local terminals via Zigbee, WiFi, Bluetooth or other short distance wireless communication (SDWC) technologies. The DMB+ base station acts both as a DMB+ bidirectional communication node and a gateway of the SDWC systems, as illustrated in Fig. 7.

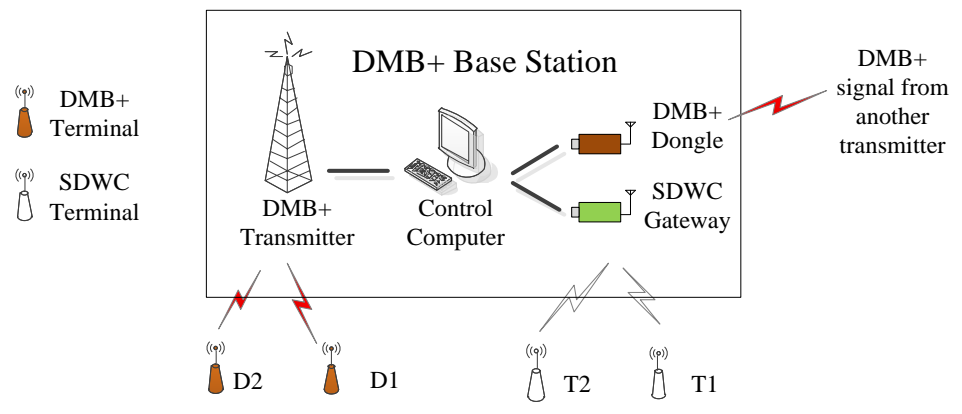

Fig. 7. The structure of the $\mathrm{DMB}+$ base station.

\section{New Applications}

\subsection{DMB+ Service for Education}

Chongqing University of Post and Telecommunications (CQUPT) is the first organization to implement DMB+ [24]. The campus covers an area of 730 acres with a building area of 700,000 square meters. One transmitter with $5 \mathrm{~W}$ power is located at the top of one high building. Fig. 8 show the DMB+ network and various public terminals on CQUPT campus.

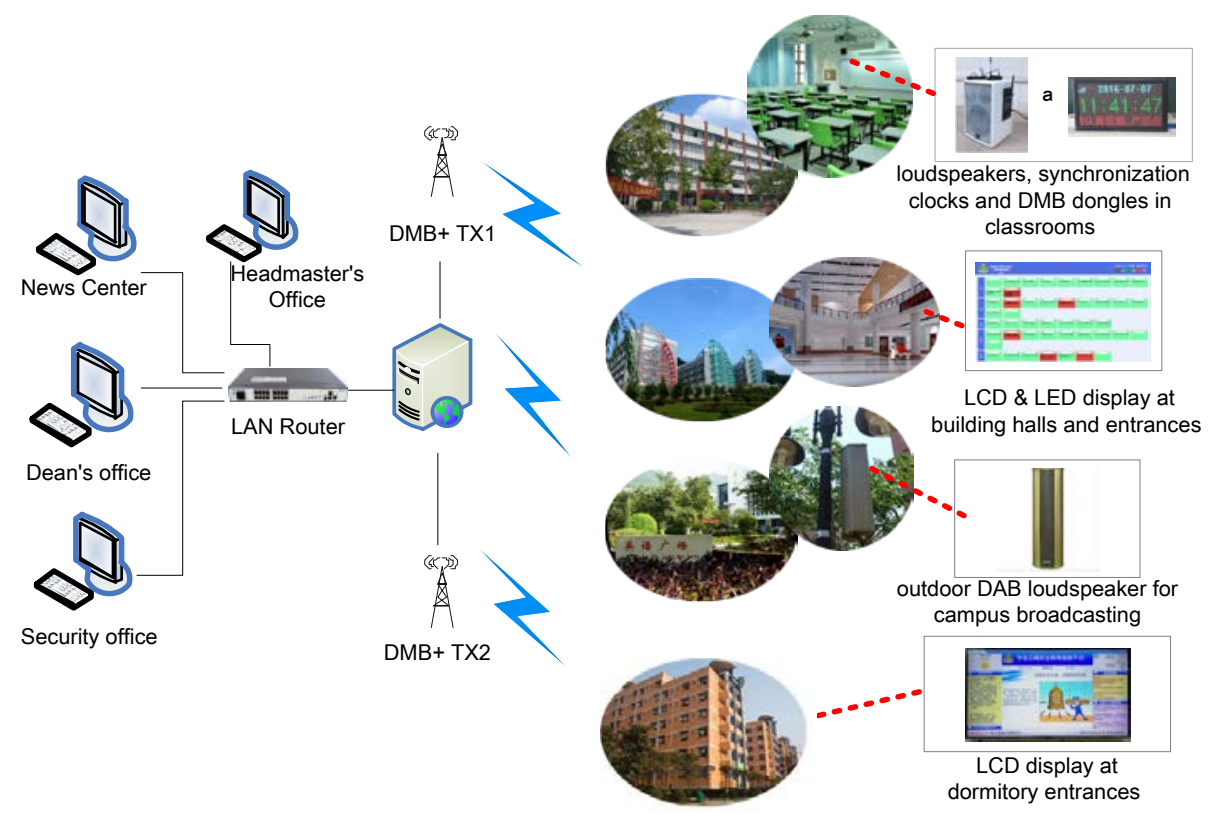

Fig. 8. DMB+ network on campus.

Program resources are encoded in MP2, H.264 or MPEG TS formats, transferred via local area network (LAN) from relevant offices to the DAB multiplexer, where all the program data 
are multiplexed and encoded into DAB transmission frames which are then modulated and up-converted to a radio frequency of $220.352 \mathrm{MHz}$. The multiplexer accepts emergency messages with the highest priority.

The receiving side includes all kinds of public terminals in use around the campus. Other than nearly 500 loudspeakers and 300 DMB dongles to drive projectors via PC in each classroom, there are 98 outdoor loudspeakers mainly for the student program and 80 LCD and 110 LED screens installed in public areas.

\section{1) As teaching facility}

It is a pity that, so far, most classrooms only have projectors and loudspeakers (via wire, or FM). Although most campuses are covered by internet and 3G/4G, these cannot be used for teaching, due to the lack of guaranteed reception quality. DMB+ can be used for listening teaching and tests, also to announce rules in voice/text before tests, to give instructions and messages in text/picture during tests and deliver videos when needed.

$\mathrm{DMB}+$ has actually become a teaching facility of the university. Taking the end-term examinations as an example, listening tests for different grades and languages usually lasted several weeks. With $\mathrm{DMB}+$, more than ten different listening tests can be arranged simultaneously so that all tests can be finished within one week.

\section{2) As administration facility}

Colleges and schools need a good atmosphere to encourage students to study hard and behave well. Outdoor loudspeakers are installed for campus broadcasting such as students' radio programs scheduled every day. Many LCD screens are placed in halls of buildings, displays videos and pictures of famous scientists, national hero, excellent students etc. as well as teaching matters.

Although every student has mobile phone and laptop, it is difficult to inform all students via individual devices. $\mathrm{DMB}+$ provides a good solution to the problem of contacting all students at once. In Chinese colleges and schools, students usually live in on-campus dormitories. For reasons of security, every student is allowed enter/exit from one entrance only. By placing one LED or LCD at the entrance, all students can be informed instantly. Administration information can be sent in this way, more efficiently, effectively and more easily than by any other methods.

Students are targets of internet financial fraud. To remind students, official warnings issued by police are repeatedly displayed on those LED or LCD at entrances. Such repeat and in time warnings can effectively reduce the risks. Fig. 9 shows LED displaying in a college.

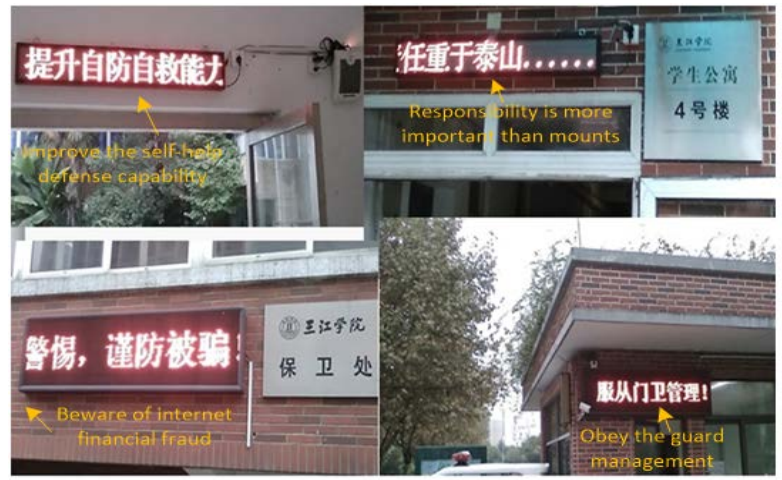

Fig. 9. DMB+ LED screens displaying warnings on campus. 


\section{2 $\mathrm{DMB}+$ Service for Social Administration}

Many Chinese cities had plans to build smart city with free WiFi covering whole area. But, so far, there is no one successful example, due to financial and engineering difficulties. Even with large investment in infrastructure, in many circumstances communication networks can fail when needed most. That was what happened in Shanghai eve of 2015 New Year. As a metropolis, Shanghai has the most advanced communication service. However, when hundreds of thousands of people gradually gathered in a hot spot, the police could not stop them and then could not disperse them because communication collapsed. As a result a stampede occurred, with injury and death. This tragedy could be easily avoided if DMB+ had been implemented. Public terminals are good at informing crowds and guiding them to leave. Fig. 10 shows an example LED displaying warning.

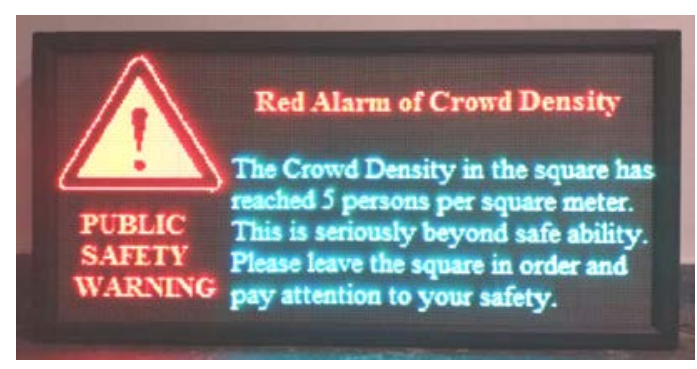

Fig. 10. An LED displaying warning text.

DMB+ is very suitable for achieving some features of smart city, and help to overcome financial and engineering difficulties. The real wireless over long distance makes engineering work easy. A transmitter of $1 \mathrm{KW}$ can cover an area of $50-80 \mathrm{~km}$ in diameter, and drive as many terminals as needed.

DMB + services for smart city applications include administration information, emergency (weather, disaster warning), security (accident, terrorism, evacuation), clarification of rumors for public calming, organization of events (festival, sports), traffic control, local news, etc. These features may look common but they are basic functions that a smart city really needs to have. In fact no one city in the world so far has implemented these services completely and reliably. Communication networks may be able to do some work on a small scale but cannot support a smart city in big scale completely and reliably. That is why so much chaos follows emergencies such as terrorist attacks in many cities.

A DMB+ platform for social administration purpose has been implemented in Tong Zhou Wan district of Nantong city. Another platform is in Hai Lin district of Taizhou city, covering an area of nearly 300 square kilometers with population of more than half million. Fig. 11 shows some public terminals in place there. 


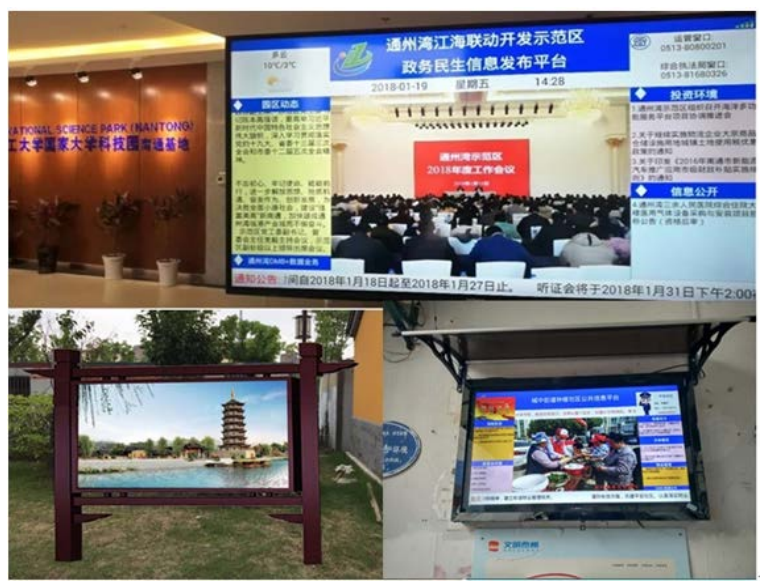

Fig. 11. DMB+ public terminals in Nantong city and Taizhou city.

\subsection{DMB+ for Alarm and Rescue Management}

China suffers frequent disasters, such as earthquakes and cyclones. Southeast Asian countries also suffer many cyclones and tsunamis. In these countries, an authoritative alarm network based on $\mathrm{DMB}+$ can be built. It can play valuable rules in every stage of an emergency.

\section{1) Precaution before an emergency}

The $\mathrm{DMB}+$ platform provides precautionary messages and relevant information such as evacuation plans, maps, scientific knowledge, and updated messages, so people can be prepared for the immanent disaster.

\section{2) Alarm in emergency}

In emergency, all public terminals are woken up within one minute to deliver sound + text + picture to create a shock effect to ensure as many people as possible get the alarm messages immediately. No other existing alarm systems can be as effective.

\section{3) Command in the course of rescue}

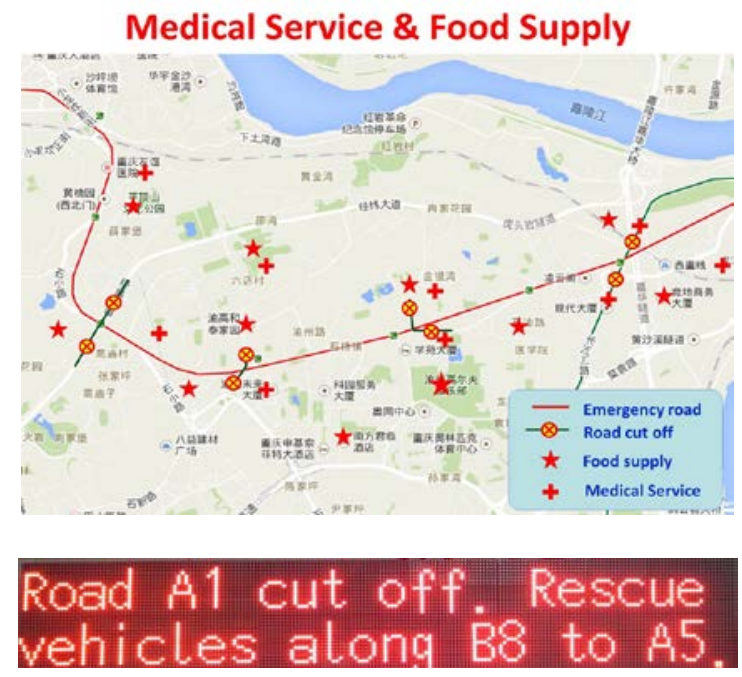

Fig. 12. LCD and LED displays for rescue information. 
The platform could be used to deliver instructions and manage evacuation via public terminals, and to coordinate medical teams, fire and rescue staff via personal compact terminals issued to individuals. This can greatly assist rescue organization. Fig. 12 shows a LCD display of rescue information and a LED display of traffic guidance. To cover power supply failure, a set of low power transmitters and receivers, as well as solar cells and battery backup powered LCDs and LEDs have been developed.

The scheme includes a function to send files e.g. in Word format to authorized terminals. This can be critical to maintain administration to isolated areas.

\section{4) Provide emergency communication}

There is still an urgent need to establish some sort of connection between the central disaster area and outside in the serious condition when communication and road are cut off. This presents a challenge.

A DMB+ base station with a portable transmitter can be quickly set up in the disaster area. Working with a $5 \mathrm{~W}$ power amplifier and a good quality directional antenna, it can send signals up to $5 \mathrm{~km}$. On the other side, an ambulance car or helicopter equipped a DMB+ base station can capture the signal and set up emergency connection with the central disaster area. The latter station can then relay information to the main communication networks enabling the disaster area to communicate with all levels of the outside authorities.

\subsection{Commercial Opportunity}

$\mathrm{DMB}+$ has been implemented in industrial parks, enterprices, commercial areas, scenic spots, hosipitals, and nuclear power plants [25]. So far there have been over $40 \mathrm{DMB}+$ platforms completed in China, and many others have expressed their enthusiasm to do the same. New $\mathrm{DMB}+$ services are useful for all walks of life, which can improve the management efficiency, safety and convenience in daily life.

$\mathrm{DMB}+$ will lead to a big quantity of new products and also promote production of other relevant electronics products. In average, one platform will need at least one transmitter, one power amplifier, may install hundreds of loudspeakers, hundreds of LED display, and hundreds of LCD display, as well as some special terminals and personal receivers. Considering China has millions of units which may eventually use DMB+, there appears a big market, which will be even bigger worldwide.

\section{Advanced Functions}

The bidirectional ability and the concept of the DMB+ base station open up more applications e.g., independent networks, remote control and management, including Industrial 4.0.

\subsection{DMB+ Networking}

An independent network can be built using DMB+ base stations as its backbone, as shown in Fig. 13. Each terminal, integrated with both $\mathrm{DMB}+$ and SWDC modules, receives data from a $\mathrm{DMB}+$ base station via the $\mathrm{DMB}+$ channel, and feeds back to the base station via the SDWC channel.

The base stations in Fig. 13 can communicate with each other. The base station can also act as a relay node, which receives a message from a base station, and then inserts to its own BCC and forwards to another base station. In this way, more $\mathrm{DMB}+$ base stations are able to 
communicate with others. With suitable routing protocol, the message can be automatically relayed in a self-organized manner, and thus a self-organized independent network will be established.

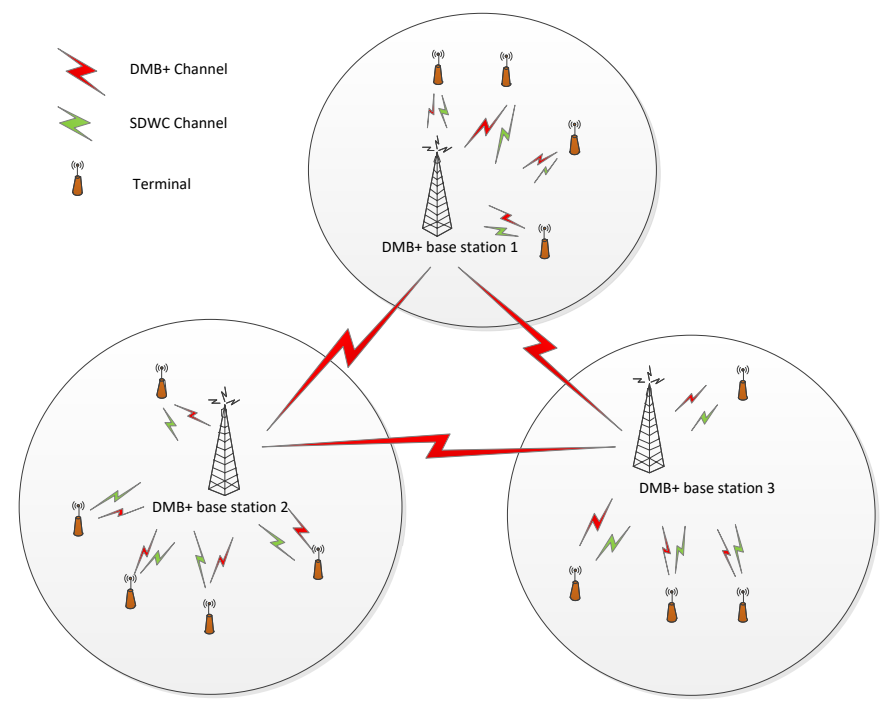

Fig. 13. The DMB+ base stations and networking.

To build such a network, some practical issues need to be considered. The maximum distance between two adjacent DMB+ base stations is 60-80 kilometers. This requires enough power amplification of 1-2 KW normally. For the frequency of Band III, a terrestrial DMB+ transmitter can only send signal up to 80 kilometers, due to the earth curvature and the limited antenna height. Unlike the single frequency network (SFN) of DAB, the transmitting frequencies of the adjacent $\mathrm{DMB}+$ base stations are different, as cellular network does. The DMB receiver equipped in a $\mathrm{DMB}+$ base station has to scan the signals of other DMB+ base stations repeatedly to detect the messages sent to it. The scan time can be significantly reduced if only a few frequencies are chosen with a proper network planning.

The DMB+ base station can communicate with the local SDWC terminals through the SDWC gateway (e.g., a LoRa or Zigbee dongle) equipped to it. All the local messages are packed and multiplexed in the BCC of the DMB+ base station, and then broadcasted out. In order to delivery messages to a long distance beyond adjacent $\mathrm{DMB}+$ base stations, i.e., in relay mode, a routing table is added to each message carried in the BCC of the $\mathrm{DMB}+$ base station. Because each DMB+ base station has known geographical positions (by presetting, or obtaining from a GPS receiver), the geographical location based routing protocol [26] can be used, as the wireless sensor network (WSN) does. Fig. 14 shows the final packet of each message in the BCC, which is composed of the synchronization bytes, the packet head, the routing table and the message data. Fig. 15 illustrates the data paths between $T_{1,1}$ and $T_{3,2}$ in a DMB+ network relaying 3 base stations, where $T_{i, j}$ stands for the $j$-th SDWC terminal of the $i$-th base station, and $M_{i, j}$ is the message sent by $T_{i, j}$.

The DMB+ network can be used for communications in a large area, where communication infrastructure is absent or behaves unsatisfactorily, such as in big industrial factories or remote zones. Organizations such as Met office or traffic control center can afford to set up their 
self-owned independent networks. Such network will ensure information security and not be affected by slowdown or crackdown of commercial networks.

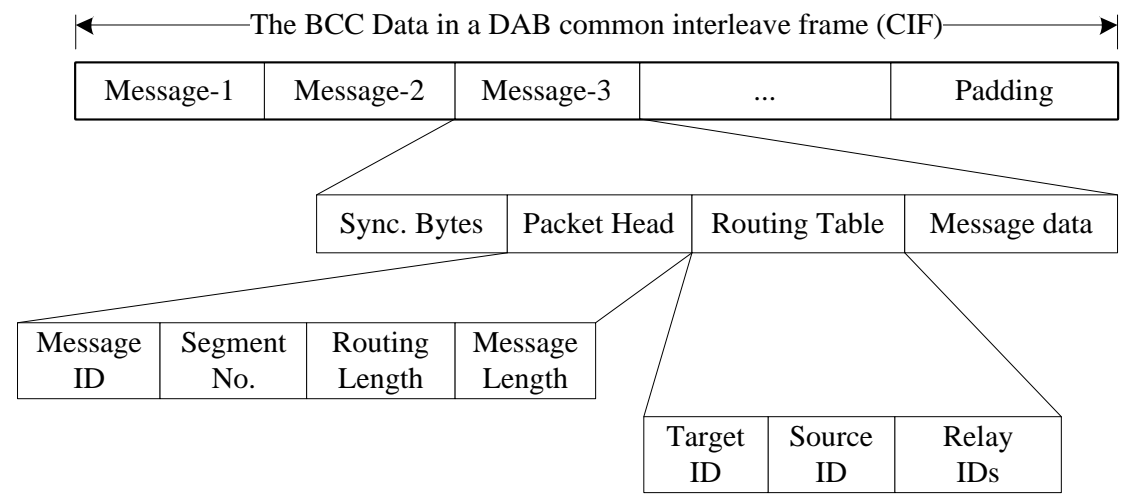

Fig. 14. The data structure of the BCC and the messages.

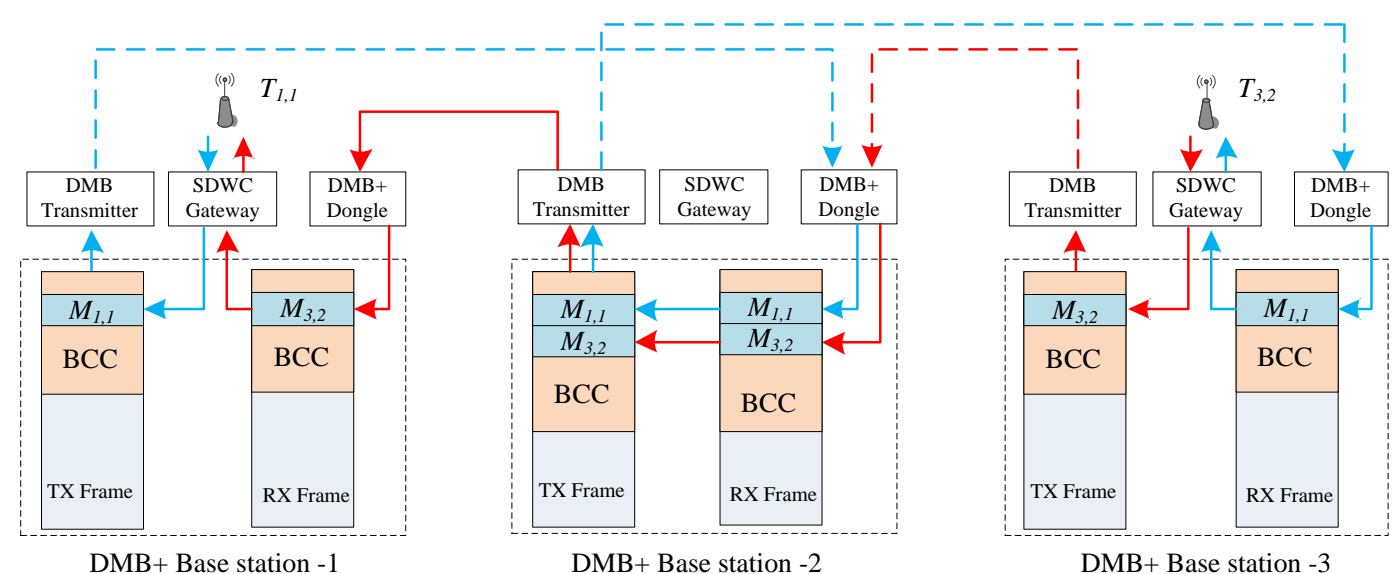

Fig. 15. The data paths in a $\mathrm{DMB}+$ network with 3 base stations.

The shortcomings of DMB+ networking are limited data bandwidth, unavoidable delivery delay (due to the operations of time de-interleaving and frequency scanning of the DMB receiver) and limited covering distance of SDWC. More researches are needed to improve these parameters. Anyway, DMB+ networking focuses on special domains, not for personal usage.

\subsection{Remote Control and Management}

Taking a factory as an example, each workshop can set up a DMB+ base station with the ability to communicate externally to other $\mathrm{DMB}+$ base stations in the factory. Locally the $\mathrm{DMB}+$ base station can send data to all equipment inside the workshop. Again the feedback from any equipment to the base station is achieved by SDWC channels. In this way, all machines in every workshop can be managed by the control center of the factory.

Fig. 16 shows such a scheme. It can be better organized, more reliable, have higher time accuracy, and greater cost effectiveness. This scheme might be extended as the data exchanging basis for implementing Industry 4.0. 


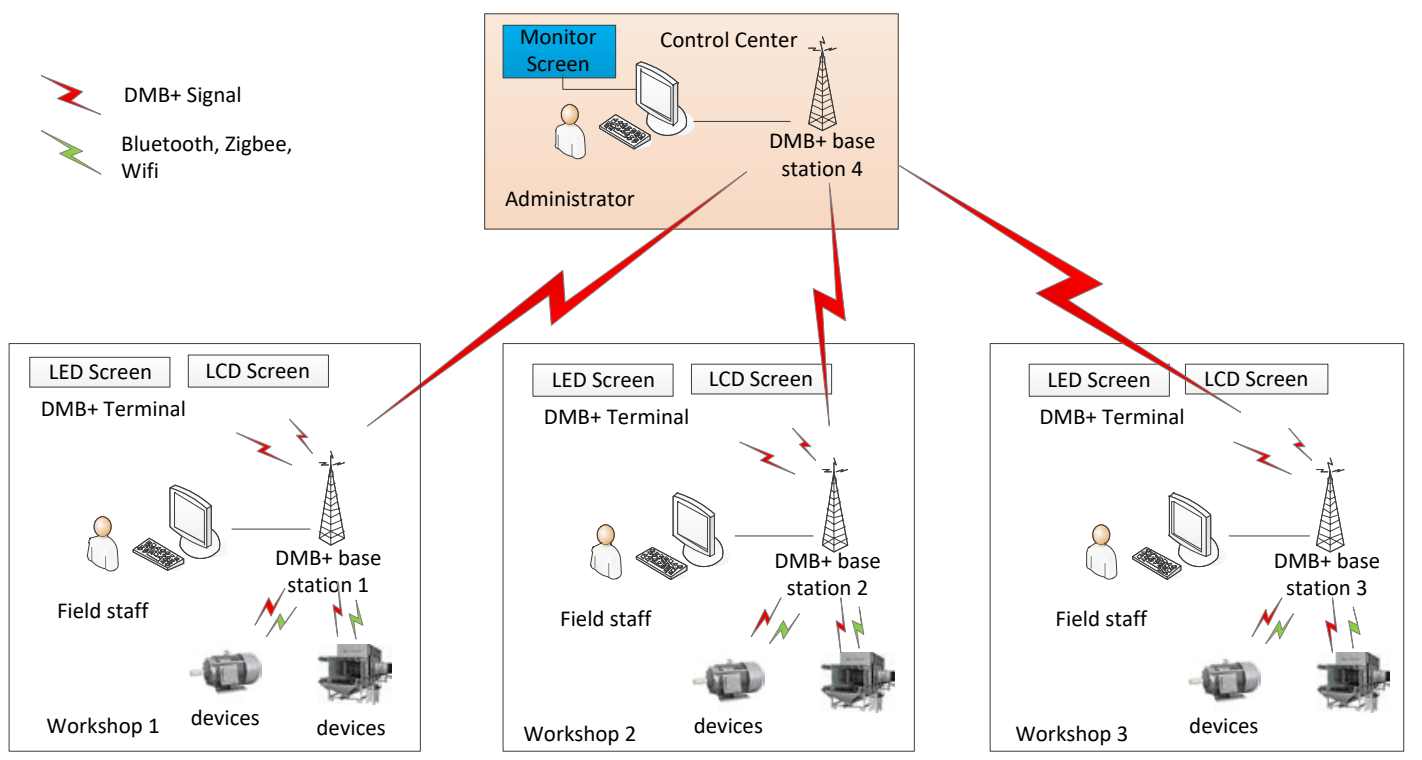

Fig. 16. DMB+ scheme for industry management and remote control.

\section{Conclusions}

DMB+ has inherent advantages for public applications by units, authorities and organizations. Those reported applications have shown better performance, reliability, efficiency, and lower cost, compared with the traditional DAB/DMB and other communication techniques. DMB+ also shows potentials for advanced applications such as independent networking and industrial control and management.

We strongly recommend that the digital broadcasting focus should shift from radio/TV programs to broader applications. We believe such a shift could revolutionalise the DAB and DMB market, massively increasing its size and opening it up to become dominant in digital broadcasting - a complimentary addition to existing communication systems and a huge commercial opportunity.

\section{References}

[1] Radio Broadcasting Systems; Digital Audio Broadcasting (DAB) to Mobile, Portable and Fixed Receivers, ETSI Standard EN300401, Jan. 2006.

[2] Digital Audio Broadcasting (DAB); DMB video service; User Application Specificationg, ETSI Standard TS102428, Jun. 2005.

[3] J. Jensen, "Lets do it digital," in Proc. of Workshop of Public Application of DMB, Chongqing, China, Oct. 2013.

[4] G. Garfors, "Diversity and flexibility of Eureka-147," in Proc. of Workshop of Public Application of DMB, Chongqing, China, Oct. 2013.

[5] Y. Lee, S. Lee, Y. Kim, S. Lee, Z.Yim, B. Choi, S. Kim, and J. Seo, "Field trials for terrestrial digital multimedia broadcasting system," IEEE Transactions on Broadcasting, vol. 53, no. 1, pp. 425-433, Mar. 2007. Article (CrossRef Link). 
[6] G. Wang, H. Zhang, and M. Lu, "Developmental trend of digital broadcasting in China (in Chinese),” China Science Bulletin (Chinese Version), vol. 59, no. 23, pp. 2320-2327, 2014. Article (CrossRef Link)

[7] G. Wang, H. Zhang, Lu Bian, X. Feng, Z. Zhu, and X. Zhang, "DMB +, a novel data transmission technique (in Chinese)," Journal of Chongqing University of Posts and Telecommunications (Chinese Version), vol. 29. no. 5, pp. 580-589, 2017.

[8] G. S. Paschos, C. P. Li, E. Modiano, K. Choumas, and T. Korakis, "In-network congestion control for multirate multicast," IEEE/ACM Transactions on Networking, vol. 24, no. 5, pp. 3043-3055, Oct. 2016. Article (CrossRef Link)

[9] X. Zhang and A. Papachristodoulou, "Improving the performance of network congestion control algorithms,” IEEE Transactions on Automatic Control, vol. 60, no. 2, pp. 522-527, Feb. 2015. Article (CrossRef Link)

[10] S. Becker, "Learning from the 2011 great east Japan disaster: insights from a special radiological emergency assistance mission," Biosecurity and Bioterrorism: Biodefense Strategy, Practice, and Science, vol. 9, no. 4, pp. 394-404, Dec. 2011. Article (CrossRef Link)

[11] Y. Ran, "Considerations and suggestions on improvement of communication network disaster countermeasures after the Wenchuan earthquake," IEEE Communication Magazine, vol. 49, no. 1, pp. 44-47, 2011. Article (CrossRef Link)

[12] S. Kiyomoto, K. Fukushima, and Y. Miyake, "Security issues on IT systems during disasters: a survey,” Journal of Ambient Intelligence and Humanized Computing, vol. 5, no. 2, pp. 173-185, 2014. Article (CrossRef Link)

[13] G A. Kumbhar, F. Koohifar, İ. Güvenç, and B. Mueller, “A Survey on legacy and emerging technologies for public safety communications,” IEEE Communications Surveys \& Tutorials, vol. 19, no. 1, pp. 97-124, 2017. Article (CrossRef Link)

[14] I. Jeon, M. Song, S. Chang, and S. J. Choi, “A signaling emergency alert system multiplexed with T-DMB channel for emergency alert service,” IEEE Transactions on Consumer Electronics, vol. 61, no.1, pp. 16-23, Feb. 2015. Article (CrossRef Link)

[15] M. Song, S. Chang, and Y. T. Lee., “A wake-up consumer device for enhanced emergency alert service in T-DMB systems,” IEEE Transactions on Consumer Electronics, vol. 61,no. 3, pp. 286-294, Aug. 2015. Article (CrossRef Link)

[16] H. Park, S. Jeong, E. Jung, H. Lee and Y. Lee, "Location based disaster information distribution platform for South Korea,” in Proc. of Int. Conf. on Platform Technology and Service, Busan, South Korea, pp. 1-4, 2017. Article (CrossRef Link)

[17] P. Falkowski-Gilski, "Transmitting alarm information in DAB+ broadcasting system," in Proc. of Signal Processing: Algorithms, Architecture, Arrangement, and Application, Poznan, Poland, pp. 217-222, 2018. Article (CrossRef Link)

[18] P. Danielis, H. Puttnies, E. Schweissguth and D. Timmermann, "Real-time capable internet technologies for wired communication in the industrial IoT - a survey,” in Proc. of IEEE 23rd Int. Conf. on Emerging Technologies \& Factory Automation, Turin, Italy, pp. 266-273, 2018. Article (CrossRef Link)

[19] M. Wollschlaeger, T. Sauter and J. Jasperneite, "The future of industrial communication: automation networks in the era of the Internet of Things and Industry 4.0," IEEE Industrial Electronics Magazine, vol. 11, no. 1, pp. 17-27, Mar. 2017. Article (CrossRef Link)

[20]H. Zhang, G. Wang, M. Lu, D. Wang and P. Xu, "Emergency warning and bidirectional communication via digital audio broadcast," IEEE Transactions on Consummer Electronics, vol. 65, no. 2, pp. 150-159, May 2018. Article (CrossRef Link)

[21] G. Wang, H. Zhang, M. Lu, T. Jiang, and G. Guo, "Low-cost low-power ASIC solution for both DAB+ and DAB audio decoding,” IEEE Transactions on VLSI Systems, vol. 22, no. 4, pp. 913-921, 2014. Article (CrossRef Link)

[22] H. Zhang, M. Lu, and G. Wang, “A high integration and low power consumption DAB baseband chip,” in Proc. of Int. Conf. on Solid-state \& Integrated Circuit Technology, Shanghai, China, pp. 1484-1486, 2006. Article (CrossRef Link) 
[23] H. Zhang, G. Wang, M. Lu, et al., “A high performance and low power consumption USB DMB receiver,” in Proc. of 2011 Int. Conf. on Computer Science and Service Systems, Nanjing, China, pp. 1931-1934, 2011. Article (CrossRef Link)

[24] Y. Deng and C. Shen, "The DAB applications in Chongqing University of Posts and Telecommunications (in Chinese),” Audio Engineering (Chinese Version), vol. 38, no. 12, pp. 98-101, 2014.

[25] Z. Li, B. Chen, H. Zhang, and P. Xu, "DMB-based wireless digital broadcast system for nuclear stations,” in Proc. of 2017 Annual Meeting on Information Technology in Power Industry, Nanning, China, pp. 134-138, Nov., 2017.

[26] Naveen K.P. and A. Kumar, "Relay selection for geographical forwarding in sleep-wake cycling wireless sensor networks,” IEEE Transactions on Mobile Computing, vol. 12, no. 3, pp. 475-488, 2013. Article (CrossRef Link)

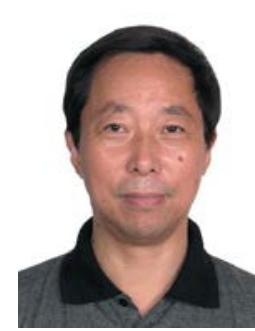

Guoyu Wang received the B.S. and M.S. degrees in electronic engineering from Southeast University, and Tsinghua University, China, in 1982 and 1984, respectively. He received the Ph.D. degree from University of Edinburgh, UK in 1994.

He has been a professor of Chongqing University of Posts and Telecommunications, China, since 2004. His current research interests include IC design, DMB+ system and application. Professor Wang was one of the pioneers of the CMOS image sensor, and was awarded the Rank Prize in 2008 for "his outstanding contribution to the science and application of opto-electronics”.

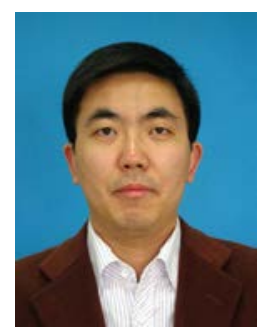

Hongsheng Zhang received the B.S., M.S. and Ph.D. degrees in electronic engineering, all from Xi'an Jiaotong University, China, in 2001, 2004 and 2012, respectively.

He has been with Chongqing University of Posts and Telecommunications, China, since 2004, and is currently a professor. He has successfully designed two DAB baseband decoder chips and several DAB commercial receivers. His current research interests include the high integration $\mathrm{DAB} / \mathrm{DMB}$ transmitter and receiver design, and the new applications of $\mathrm{DAB}$ and DMB. 